\title{
Engineering design of a grain silo and a bucket elevator for a combined unit for hopper preparation and seeding of grain crops
}

\author{
Kirill Nemtinov ${ }^{1, *}$, Alexsey Eruslanov ${ }^{1}$, and Yulia Nemtinova $^{1,2}$ \\ ${ }^{1}$ Tambov State Technical University, 392000, Sovetskaya st., 106, Tambov, Russia \\ 2 Tambov State University named after G.R. Derzhavin, 392000, Internatsional naya st., 33, Tambov, \\ Russia
}

\begin{abstract}
In this paper, we present the results of engineering design of components of a grain hopper and a bucket elevator for a combined unit for soil preparation and sowing of grain crops. The grain hopper has compartments for seeds and fertilizers. A coil-type metering device is also separated for seeds and fertilizers. The drive of the metering device for seeds and fertilizers is done by the rear wheels of the rolling device through a variator, which also serves to adjust seeds supply. On the same shaft with the metering device there is a sprocket, which transmits rotation moment to the bucket elevator through a chain of PR type. Due to special design characteristics of the grain hopper shape, seeds enter the coil type metering device by gravity. A similar operation is done for fertilizers. Portions of fertilizers and seeds fall into a small tank, joint for grain and fertilizers, from where the elevator's buckets deliver them to the distribution device. Seeds and fertilizer fall on the distributing device al ong the tray and then on rotating cone with blades, which uniformly distribute grain and fertilizers to all drill tubes. The developed units were organically included in the design of the entire combined unit. The obtained results allowed us to distinguish the following advantages of the developed designs of the hopper and the bucket elevator: a single metering unit for all sowing machines; easy access to the main units and mechanisms and their maintainability; ease of off-season maintenance; use of a large number of typical domestically produced units and mechanisms.
\end{abstract}

\section{Introduction}

The design stage plays an important role for the technical level of future agricultural machinery, as at this stage designers set the main technical parameters and design solutions for new agricultural machines, the shortcomings of which are difficult and often impossible to be corrected at subsequent stages. Currently, integrated systems for computer-aided design of technological agro-complexes are widely used. Their use significantly increases the efficiency of designer's work by automating routine design operations and documentation for the specific design solution. However, the problem of obtaining the

\footnotetext{
*Corresponding author: nemtinov@ mail.gaps.tstu.ru
} 
optimal variant (or several variants which are close to the optimal one) for real operating conditions of agricultural machinery remains unsolved [1 - 5].

The solution of this problem is possible on the basis of an automated information system of decision support for agricultural machinery design, the main function of which is to study the main parameters of technological processes for its use in agriculture, including system, information, economic and technological analysis.

To solve this problem, the authors have proposed a technology of computer-aided design of prospective sowing complexes reflected in the works [6 - 10], which:

1) simultaneously takes into account:

- presentation of the set of design tasks for technological agro-complexes (automated selection of the structural scheme of a sowing complex, typical units and mechanisms, as well as design of original units and the layout of all units of the complex) in the form of a single system using the theory of complex systems and a single information base,

- integrated assessment of design solutions (from economic and technological standpoints);

2) provide:

- increased intellectual foundation of data processing in the research field;

- significant reduction of time and costs for the design of sowing complexes;

- notable reduction in the number of designers errors and their elimination at the early design stages ensuring manufacturability - convenience and ease of functioning of individual units and the whole complex.

\section{Engineering design of components of the combined unit}

This work is devoted to egineering desigh of a grain hopper and a bucket elevator of a combined unit for soil preparation and sowing of grain crops.

Consumers have set the task for creating such a design, that would provide:

- single metering unit for all sowing machines;

- easy access to the main components and mechanisms and their maintainability;

- easy off-season maintenance;

- use of a large number of typical domestically produced units and mechanisms.

For engneering design, the authors have used 2D-3D drawing systems ( $A$ utoCAD and COMPASS). Mechanical calculations for the units of the complex were performed in accordance with GOST 26711-89 [4]. In addition, the authors have used the MathCad system, which allows automating the calculations [11 - 14].

The results of their development are presented in figures 1-4. A grain hopper has compartments for seeds and fertilizers. A coil-type metering device for seeds and fertilizer is also separated for seeds and fertilizers. The drive of the metering device for seeds and fertilizers is done by the rear wheels of the rolling device through a variator (different for fertilizer and seeds), which also serves to adjust seeds supply. On the same shaft with the metering device, there is a sprocket which transmits rotation moment to the bucket elevator through a chain of the PR type. 


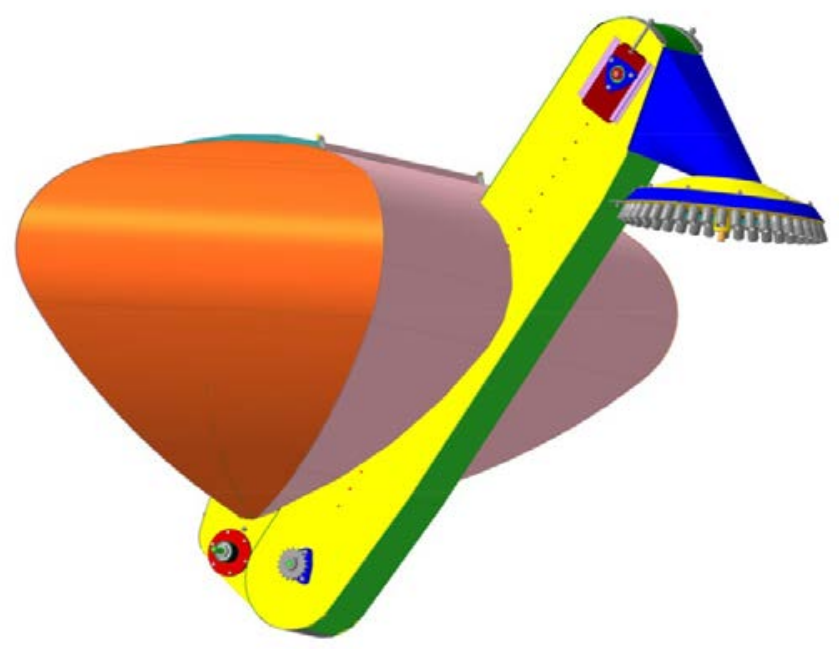

Fig. 1. 3D view of a hopper and a bucket Elevator model with a metering device.

Inside the body of the bucket elevator there is a stretched chain of the PRP type with brackets, to which buckets are attached to transport seeds to the distribution device. Seed and fertilizer dispenser is rotated through the angle-type gear (not adjustable). There is easy access to all mating details, the PRP chain tension is done by the means of two adjusting screws.

Due to characteristic design features of the hopper's shape, seeds enter the coil type metering device by gravity. A similar operation occurs with fertilizers. Portions of fertilizers and seeds fall into a small tank, joint for grain and fertilizers, from where elevator's buckets deliver them to the distribution device. Seeds and fertilizer fall on the distributing device along the tray and on rotating cone blades, which uniformly distribute grain and fertilizer to all of the forty two drill tubes. The metering device includes hatches for cleaning of the hopper from the remnants of seeds and fertilizers, which simplifies interseasonal maintenance of the sowing machine.

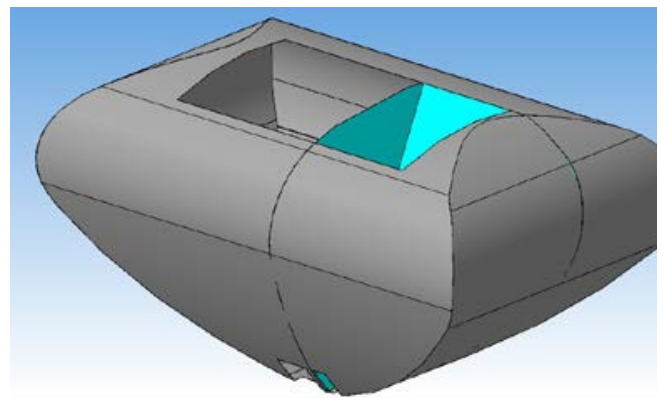

a)

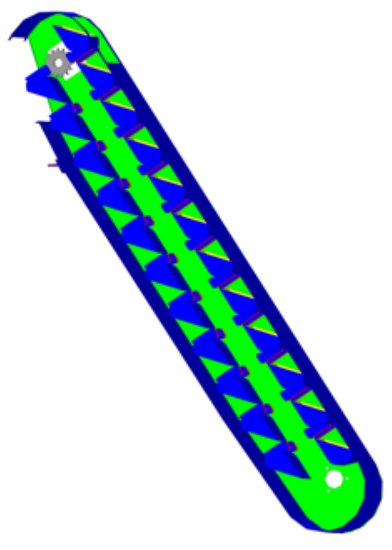

b)

Fig. 2. (a, b) 3D models: grain hopper-a), bucket elevator-b) 


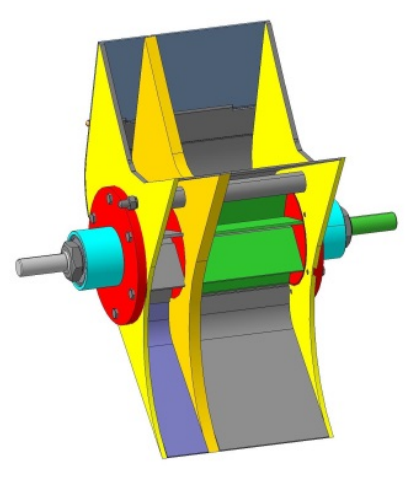

a)

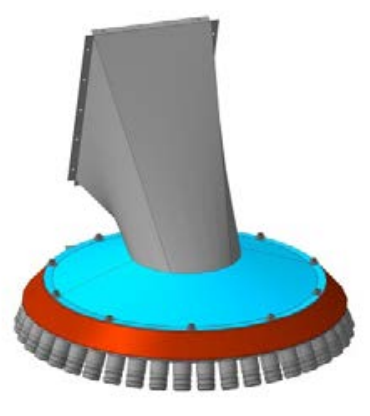

b)

Fig. 3. (a, b) 3D models: coil type metering device-a), distributing device-b)

Along the drill tubes, seeds and fertilizer are delivered to the grain-dirll feeds (42 units) by gravity for seeding.

The developed design of the grain hopper and the bucket elevator using the technology described in [5] was organically included in the design of the entire sowing complex. The General 3D view of its model is shown in figure 4.

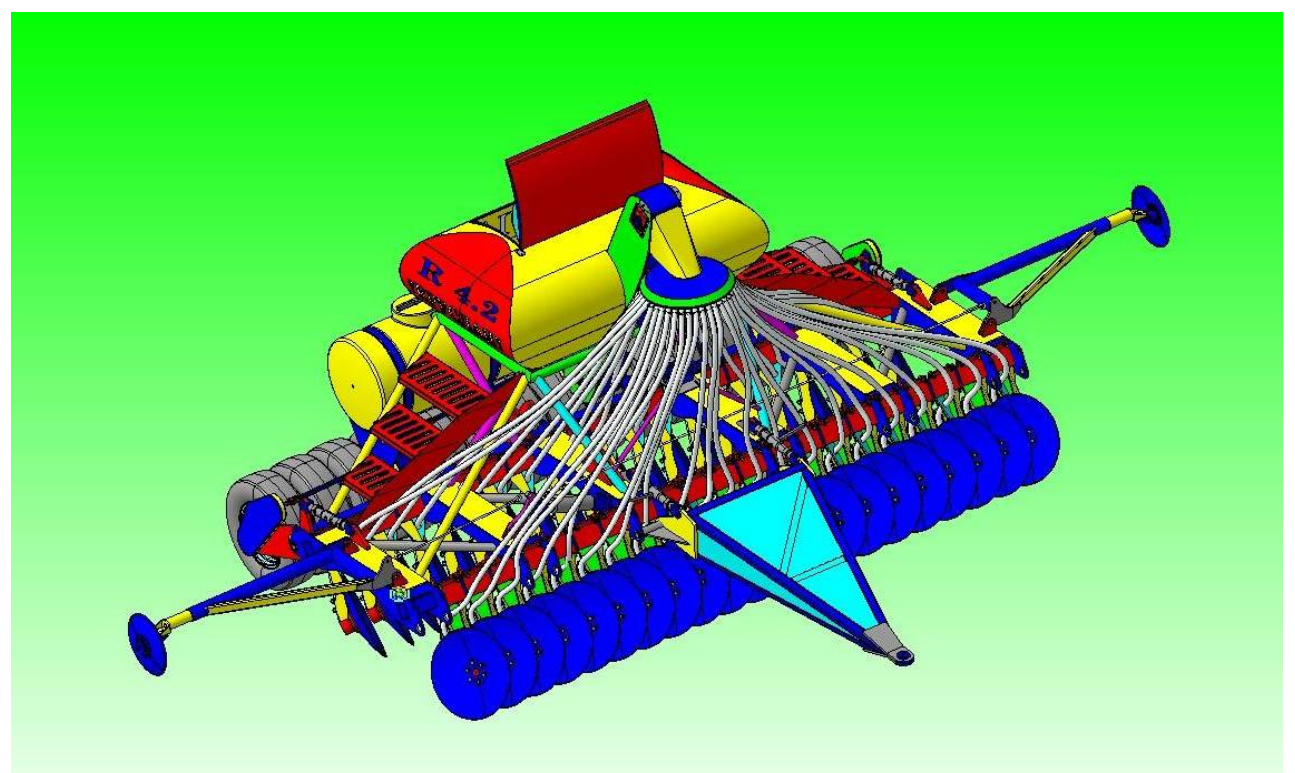

Fig. 4. 3D model of the sowing complex for grain crops.

\section{Results and discussion}

In accordance with the developed design documentation of the sowing complex, LLC "K B ERUSLAN" has made a prototype. Experiments with the combined unit, which were carried out in the fields of the Rostov region, in the Sholokhov district on the lands of J SC 
"B orets", have shown high efficiency of the proposed design of the grain hopper, the bucket elevator and the entire unit.

Expected average annual economic effect from a small-scale production, using the designed complex on the fields of Rostov region, is about 450000 rubles due to low cost of the complex and high efficiency of its operation.

Thus, the obtained results allowed distinguishing the following advantages of the developed design of the hopper and the bucket elevator of the combined unit for soil preparation and sowing of grain crops:

- single metering unit for all sowing machines;

- easy access to the main components and mechanisms and their maintainability;

- easy off-season maintenance;

- use of a large number of typical domestically produced units and mechanisms.

\section{References}

1. V.A. Nemtinov, Yu.V. Nemtinova. Journal of Computer and Systems Sciences International. 44(3), 389-398 (2005)

2. V.G. Mokrozub, V.A. Nemtinov A.V. Mokrozub. Chemical and Petroleum Engineering. 53(5-6), 326-331 (2017)

3. L. Lijing. Transactions of the Chinese Society of A gricultural Engineering. 31(11), 40$45(2015)$

4. V.G. Mokrozub, V.A. Nemtinov. Chemical and petroleum engineering, 51(7-8), 31-35 (2015)

5. V.A. Nemtinov, N.A. Bolshakov and Y.V. Nemtinova. M ATEC W eb of Conferences 129 ICM TM TE (2017)

6. G.V. Prasanna K umar, B. Srivastava, D.S. Nagesh. Computers and Electronics in A griculture. 65(1), 26-35 (2009)

7. J.M. Wang, L. Zhang, Y.B. Liu, X.N. Mo, G.Q. Ren. Computer Integrated M anufacturing Systems. 16(10), 2017-2023 (2010)

8. V.G. Mokrozub, K.D. Manuilov, V.V. Gorshkov, T. S. Gorshkova. Chemical and Petroleum Engineering. 51(9-10), 613- 617 (2016)

9. A.B. Borisenko, S.V Karpushkin. Journal of Computer and Systems Sciences International. 53(3), 410-419 (2014)

10. A. Ivannikov, V. Kulagin, A. Romanov, B. Pozdneev. EWDTS-2016 Proceedings, 14th IEEE EAST-WEST DESIGN \& TEST SYMPOSIUM (2016)

11. E.N. Malygin, V.G. Mokrozub, V.A. Nemtinov. MATEC W eb of Conferences 129 ICM TMTE (2017)

12. V. V amerali, M. B ertocco, L. Sartori. Soil \& Tillage Research, 89(2), 196-209 (2006)

13. L. Y ang, X.T. He, T. Cui, D.X. Zhang, S. Shi, R. Zhang. International Journal of A gricultural and Biological Engineering, 4, 1-9 (2015)

14. T. Zhao, Y. Zhao, T. Higashi, M. Komatsuzaki. Engineering in Agriculture, Environment and Food. 5(2), 50-56 (2012) 